\title{
Empathy in Piano Duet Rehearsal and Performance: A Response to Haddon and Hutchinson
}

\author{
FRED SEDDON \\ University of Northampton
}

\begin{abstract}
This review comments upon the article "Empathy in Piano Duet Rehearsal and Performance" by Haddon and Hutchinson. This review critiques the Method and Discussion sections of the article and offers suggestions for future research. Three specific points from the method are considered relating to: dual roles as researchermusicians, the use of reflective diaries in research, and the impact on the research of the prior relationship between the authors. The unique role of "written empathy" is discussed within the context of empathic relationships. Also, this review considers how shifts from verbal to non-verbal communication may indicate movement from a "top-down" to "bottom-up" response, and how this shift is related to "empathetic attunement."
\end{abstract}

Submitted 2014 August 28; accepted 2014 October 30.

KEYWORDS: empathy, music ensemble, communication, reflection.

THE article by Haddon and Hutchinson, "Empathy in Piano Duet Rehearsal and Performance," reports the impact of empathy on the fluidity of roles between two musicians as they rehearse and perform a piano duet. The notion of a "safe space" for musical collaboration is also considered. The article begins with a presentation of research in the general area of empathy. This review is comprehensive and outlines the complex, multi-faceted nature of empathy in relation to its affective, cognitive, and emotional components across different domains. The review of the literature clarifies that empathy can be a process and a capacity approached as a "bottom-up" response focusing on perceptual or sensory drivers, and a "top-down" response focusing on cognitive and attribution drivers. What is also highlighted in this section of the article is the importance of the communication component of empathy, which is of particular significance to musicians when rehearsing and performing. There then follows a presentation of prior research into empathy specifically within the music domain. This presentation of prior research is also comprehensive and well-constructed, and serves to effectively position the research project within prior literature. The article's authors articulate how their current research extends prior research in the field and they highlight the originality of their research in relation to the piano duet (at one piano). Furthermore, originality of the study surrounds the data collection process, which involved shared reflective writing. The physical constraints associated with the sharing of the piano keyboard by the musician-researchers are discussed along with the potential impact of their close physical proximity. The limitations of repertoire and distribution of musical content to the primo and secondo musical parts are discussed in terms of any potential leadership role when compared to other musical ensembles. This introduction section equips the reader with appropriate knowledge of prior research into both empathy in general and its application in the music domain. It also establishes the need for the research and the context within which it was conducted.

\section{METHOD}

The method adopted for the research is perhaps the most interesting and original part of the reported study. Much prior research has been conducted into the importance of empathy in musical ensemble rehearsal and performance; most of which has been reviewed in the introduction section of the article. Three points in the method adopted are of particular interest: 1) the combined role of researcher and musician; 2) the use of reflective diaries as a means of data collection; and 3) the relationship between the musician-researchers; although they are now colleagues, historically, their relationship was one of student and teacher. Because the musicians were both participants and researchers in their own study, the use of reflective diaries provided direct access to their thoughts in both of their roles. This potentially provided an optimal 
condition within which to capture and analyze the data as any researcher interpretation of the data is automatically validated because participants and researchers are as one. Although the dual-role reflective process employed in the research is unique, the use of reflection as part of the data collection process in this type of research has previously been employed. Seddon (2005) and Seddon and Biasutti (2009) included participant musician reflection through the technique of retrospective verbal protocols (RVPs) undertaken whilst watching video recordings of their rehearsals and performance. Researcher interpretations of the RVPs were then subjected to "member checks" in order to validate those interpretations. The "member checks" procedure is one where participants are asked to inform researchers if they have accurately described their experience and produced a "recognizable reality" (Brown \& Gilligan, 1992; Lincoln \& Guba, 1985; Punch, 1998; Seddon, 2005). The article under review presents an interesting development in the use of reflection during data collection as it could be argued that when researchers are also participants then data collection through participant reflective diaries is a more efficient procedure than RVPs and could provide more detailed and accurate insight into the participants' thought processes. An interesting question for future research could be: does the combination of researcher and participant in the study exert any extraneous influence that could impact upon the research process? There is precedent for researcherparticipant process in prior research, as during some ethnographic research it can be argued that the researcher is also a participant. It must also be acknowledged that the article's authors probably considered this point as they "maintained a critical distance" of several months between data collection and analysis perhaps to allow for this potential conflict of roles. The prior relationship of teacher and student between the researcher-musicians in the study begs the question: can a former student ever perceive themselves as a true equal when working in collaboration with a former teacher? Will the student always subconsciously defer to the former teacher during collaboration? This is an interesting question that is worthy of future empirical research in the fields of both music and methodology. The "power dynamic" between the researcher-musicians in this study is important, as prior research has demonstrated the importance of democratic and leaderless ensembles in producing group cohesion and optimal performance (Sawyer, 2005; Kenny \& Gellrich, 2002). Once more, it should be acknowledged that the article's authors have considered this very point in their discussion of "leveling their relationship" as part of the socio-emotional role of empathy. Also, in this case, the former student found the colleague-duet partner adopting a "teacher mode" to be a positive experience and very helpful. However, it is important to acknowledge that whilst mitigated in the current study, this may not always be the case.

\section{WRITTEN EMPATHY AND EMPATHETIC ATTUNEMENT}

In the case studies reported in the article, the authors indicate that, as musician-researchers, they were able to resolve potential conflict through negotiation and improve their musical interpretation and expression by achieving a sense of "empathetic attunement." They make an important distinction here between verbal and non-verbal communication that is enhanced by empathic responses to others. The authors also introduce the concept of "written empathy," which adds a new dimension to the role of empathy during communication. It is interesting to note that although the researcher-musicians had a relationship as student and teacher and subsequently worked together as colleagues in the same department for a period of six years, they had never worked together as a duet partnership. This lack of experience in duet partnership may explain their gradual shift from verbal communication towards greater amounts of time spent playing together as they developed their non-verbal, empathetic attunement through their developing musical relationship. Prior research has established that a well-developed musical relationship between players, established over a significant period of time, can have a positive impact on the resolution of potential conflict (Murnighan \& Conlon, 1991). Differences in interpretation and expression, which could lead to conflict, can be resolved through playing together rather than engaging in verbal communication (Murnighan \& Conlon, 1991). The shift from verbal communication to non-verbal communication through empathetic attunement may exemplify movement from a "top-down" to a "bottom-up" response. The generation of "safe space" is also very important in establishing empathetic attunement between musicians, and trust forms an essential part of this process (Seddon, 2005). Trust is something that often takes time to develop, and the long-term relationship between the researcher-musicians as student-teacher, colleagues, and duet partners in this study probably allowed this trust to develop. Furthermore, the researcher-musicians' prior relationship as student and teacher could also have contributed to their empathetic attunement through "empathetic intelligence," which is the inter-subjective engagement between educator and student (Arnold, 2004). 
Haddon and Hutchinson suggest that this may be the case in their discussion of fluidity of roles, drawing analogies between the roles of therapist/counsellor-client and student-teacher relationships.

\section{CONCLUDING REMARKS}

The article clearly establishes the importance of including reflective diaries as a data collection tool in future studies examining the impact of empathy on musical rehearsal and performance. The study also examines the benefits of musician participants acting as researchers in future studies, but perhaps further study is required to examine the effects of any potential conflict resulting from the amalgamation of these roles. It is intriguing to consider the differences between sharing a physical space with other musicians and actually sharing an instrument. Can this sharing process enhance the empathic relationship between the musicians through physical proximity, or does it confound it through physical constraint? Another interesting question is: how does the nature of musicians' prior relationships impact upon their ability to develop trust, create a safe place, and achieve empathetic attunement? The article seeks to explore some of these areas, but further research could offer a more in-depth contribution to knowledge surrounding these important questions.

\section{REFERENCES}

Arnold, R. (2004). Empathic intelligence: Relating, educating, transforming. Sydney: University of New South Wales Press.

Brown, L. M., \& Gilligan, C. (1992). Meeting at the crossroads: Women's psychology and girl's development. Cambridge, MA: Harvard University Press.

Kenny, B. J., \& Gellrich, M. (2002). Improvisation. In R. Parncutt \& G. E. McPherson (Eds.), The science \& psychology of music performance: Creative strategies for teaching and learning (pp. 117-134). Oxford: Oxford University Press.

Lincoln, Y., \& Guba, E. (1985). Naturalistic enquiry. Beverly Hills, CA: Sage.

Murnighan, J. K., \& Conlon, D. E. (1991). The dynamics of intense work groups: A study of British string quartets. Administrative Science Quarterly, 36, 165-186.

Punch, K. F. (1998). Introduction to social research: Quantitative and qualitative approaches. London: Sage.

Sawyer, K. (2005). Music and conversation. In D. Miell, R. MacDonald, \& D. J. Hargreaves (Eds.), Musical communication (pp. 45-60). Oxford: Oxford University Press.

Seddon, F. A. (2005). Modes of communication during jazz improvisation. British Journal of Music Education, 22(1), 47-61. doi:10.1017/S0265051704005984

Seddon, F. A. \& Biasutti, M. (2009). A comparison of modes of communication between members of a string quartet and a jazz sextet. Psychology of Music, 37(4), 395-415. doi:10.1177/0305735608100375 